\title{
Genetic analysis of skinfold thickness and its association with body condition score and milk production traits in Chinese Holstein population
}

\author{
H. Zhang, ${ }^{1}$ A. Liu, ${ }^{1,2}$ X. Li, ${ }^{1}$ W. Xu, ${ }^{1}$ R. Shi, ${ }^{1}$ H. Luo, ${ }^{1}$ G. Su, ${ }^{2}$ G. Dong, ${ }^{3}$ G. Guo, ${ }^{3}$ and Y. Wang ${ }^{1 *}$ \\ ${ }^{1}$ Laboratory of Animal Genetics, Breeding and Reproduction, Ministry of Agriculture of China, National Engineering Laboratory of Animal Breeding, \\ College of Animal Science and Technology, China Agricultural University, Beijing 100193, China \\ ${ }^{2}$ Center for Quantitative Genetics and Genomics, Department of Molecular Biology and Genetics, Aarhus University, Tjele 8830, Denmark \\ ${ }^{3}$ Beijing Sunlon Livestock Development Co. Ltd., Beijing 100176, China
}

\section{ABSTRACT}

The skin has many important roles in dairy cattle, and skinfold thickness could be used as an indicator of body fat deposition. The objectives of this study were to estimate genetic parameters of skinfold thickness and to explore its association with body condition score (BCS) and milk production traits in a Chinese Holstein population. Skinfold thicknesses over the neck (STN) and the last rib (STR), BCS, and test-day records of milk production traits were available for 6,416 lactating Holstein cows in the summers of 2015 and 2016 in Beijing, China. Multi-trait animal models were used to estimate variance and covariance components using the DMU software. The average STN was $7.15 \pm 1.28$ $\mathrm{mm}$, and the average STR was $11.76 \pm 1.95 \mathrm{~mm}$ (mean \pm standard deviation). Estimated heritability was 0.13 \pm 0.03 for STN and $0.26 \pm 0.04$ for STR. We detected a high genetic correlation $(0.79 \pm 0.08$; heritability \pm standard error) between STN and STR. Genetic correlations between skinfold thickness and BCS were low to moderate: 0.18 between STR and BCS, and 0.33 between STN and BCS. Genetic correlations between skinfold thickness and milk yield, milk fat percentage, and milk protein percentage were negligible, ranging from -0.02 to 0.15 . Collectively, skinfold thickness is characterized as a trait with moderate heritability. Skinfold thickness is sensitive to changes in body condition or fat deposition across parities and lactation stages in milking cows, and we confirmed the complementary nature of skinfold thickness and BCS genetically as well as phenotypically by comparing their changing trends throughout lactation and across lactations. The use of skinfold thickness, together with BCS, can assist in the monitoring of changes in body fat deposition to achieve higher management precision.

Received June 8, 2018

Accepted November 7, 2018.

*Corresponding author: wangyachun@cau.edu.cn
Key words: skinfold thickness, heritability, genetic correlation, body condition score

\section{INTRODUCTION}

The skin is the outermost structure and the largest organ of cattle. Skin undertakes many functions, including protection against pathogens and excessive water loss, perspiration, sensation, and regulation of temperature and pressure (Lai-Cheong and McGrath, 2013). Thickness is one of the critical characteristics of skin, and there are 2 general methods to measure the thickness of skin in live cattle: biopsy skin measurement and skinfold measurement (Dowling, 1955). Biopsy skin measurement obtains the actual skin thickness by using a dial micrometer to directly measure a skin section that is removed surgically from the body surface of animals (Dowling, 1955). The skinfold measurement is a widely used method in the field, which measures the skinfold using a caliper. Compared with the biopsy skin measurement, the skinfold thickness is more suitable for large-scale studies and is preferable in terms of animal welfare. Therefore, skinfold thickness has been widely used to represent skin thickness of cattle in various studies (Tucker et al., 2007; Muenchen Alfonzo et al., 2016). Previous studies have explored the factors affecting skinfold thickness, such as breed, body region, nutritional status, sex, age, and measurer (Dowling, 1955; Patel and Anderson, 1958; Hayman et al., 1966). Skinfold thickness can be measured over different body regions, but thickness over the neck and rib are frequently used in the literature because of the advantages of high repeatability and convenience of measurement for these 2 regions compared with that of other regions (Hamid et al., 2000; Tucker et al., 2007).

Skinfold thickness is reported to be related to immune response (Lepper et al., 1977; Ghebremariam et al., 2016), body fat (Bruckmaier et al., 1998), heat tolerance (Bonsma et al., 1953; Muenchen Alfonzo et al., 2016), tick resistance (Carr et al., 1974; Maiorano et al., 2016), reproduction (Siddiqui et al., 2008), and 
milk yield (Hamid et al., 2000; Kshatriya et al., 2009) in cattle. For example, high negative phenotypic correlations were observed between skinfold thickness over various body regions and milk yield in Kankrej and crossbred cattle $(1 / 4$ Holstein Friesian $\times 1 / 4$ Jersey $\times$ $1 / 2$ Kankrej, Sahiwal $\times$ indigenous; Hamid et al., 2000; Kshatriya et al., 2009).

Skinfold thickness is frequently used to estimate body fatness in human (Chen et al., 2018), black bear (Noyce et al., 2002), and chicken (Latshaw and Bishop, 2001), as body fat deposition is highly correlated with growth, health status, and product quality. Body condition score is a scoring system practiced in the management of the cattle industry to evaluate energy metabolic status and body fatness (Schröder and Staufenbiel, 2006; Roche et al., 2009). Strong relationships have been found in cattle between skinfold thickness and overall carcass fatness $(r=0.95$, anal skinfold thickness; Charles, 1974), internal fat weight $(r=0.72$, skinfold thickness over the dewlap; Gregory et al., 1998), and total body fat $(\mathrm{r}=0.69$, anal skinfold thickness; Nicholson and Little, 1989); therefore, skinfold thickness can be used to evaluate the nutritional status of dairy cows (Bruckmaier et al., 1998; Schröder and Staufenbiel, 2006). Schröder and Staufenbiel (2006) proposed in their review that skinfold thickness should be used, in addition to BCS, in nutrition management. Although it is known that skinfold thickness includes the subcutaneous fat (Bruckmaier et al., 1998) and can be easily measured objectively, little has been done to evaluate the complementarity between skinfold thickness and BCS.

Only one report in the literature noted that skinfold thickness in beef was moderately heritable and those authors estimated the heritability of skinfold thickness in the region posterior to the scapula to be $0.12 \pm$ 0.02 (Maiorano et al., 2016). To our knowledge, genetic analyses of skinfold thickness and its correlations with economically important traits have not yet been reported in dairy cattle. The objectives of this study were to estimate the heritability of skinfold thickness and its genetic associations with BCS, milk yield, milk fat percentage, and milk protein percentage in Chinese Holsteins. Results from this study could facilitate further exploration in the use of skinfold thickness for management and genetic selection in various dairy cattle populations.

\section{MATERIALS AND METHODS}

\section{Data}

Skinfold thickness, BCS, and test-day records of milk production traits were available from 9 dairy herds in
Beijing, China. Skinfold thickness of 6 and 7 herds, respectively, was measured in the summer of 2015 and the summer of 2016; and 4 herds were measured in both years. Skinfold thickness was measured over the neck and the last rib. During measurement, the measurer used one hand to pull the skin to form a fold and used the other hand to measure the folded thickness with a digital Vernier caliper (precision: $0.01 \mathrm{~mm}$ ). The skinfold thickness over the neck (STN) and skinfold thickness over the last rib (STR) were measured on either the right-hand side or the left-hand side of the body in 2015 but measured only on the right-hand side in 2016. Body condition score was evaluated as a scale from 1 to 5 with 0.5 -unit increments $(1=$ thin, $5=$ fat; Wildman et al., 1982) by 2 trained raters at the same time as skinfold thickness was being measured. Each herd was completed by several scoring groups, each using 2 raters, and BCS was analyzed as an average of the 2 raters' scores. A single record per cow for STN, STR, and BCS was analyzed, with duplicate records removed. Single test-day milk yield (MY), milk fat percentage (MF\%), and milk protein percentage (MP\%) records were taken from the official DHI services that were nearest to the date when skinfold thickness was measured. The total number of cows in the final data set was 6,416 . The numbers of observations available for STN, STR, BCS, MY, MF\%, and MP\% were 4,306, 4,330, 5,585, 5,634, 4,969, and 5,533, respectively. Pedigree data were provided by the Dairy Association of China (Beijing) and consisted of 365,855 animals, including 353,601 females and 12,254 males born from 1984 to 2016. Each animal was traced back as many generations as possible.

\section{Models}

The general linear models procedure of SAS software (version 9.1; SAS Institute, 2004) was used to test the significance of nongenetic effects. Herd, measurer, parity, lactation stage, and body side on STN and STR; herd, rater, parity, and lactation stage on BCS; and herd, year, parity, and lactation stage on MY, MF\%, and $\mathrm{MP} \%$ were tested. In this study, parities of cows were grouped into 5 levels, $1,2,3,4$, and $\geq 5$, where the fifth level included cows from parity 5 to parity 10; lactation stages were divided into 5 levels, including 1-50 d, 51-100 d, 101-200 d, 201-305 d, and >305 d. Only significant effects $(P<0.05)$ were then used in the genetic analysis. Preliminary analysis showed that parity for MY and body side for STN had no significant effects (data not shown). Variance components were estimated using a multi-trait animal model by averageinformation REML implemented in the DMU software (Madsen et al., 2006). 
Table 1. Descriptive statistics of skinfold thickness over the neck and last rib, BCS, and milk production traits

\begin{tabular}{lcrrrrr}
\hline Trait $^{1}$ & $\mathrm{n}$ & Mean & SD & CV & Minimum & Maximum \\
\hline STN & 4,306 & 7.15 & 1.28 & 0.18 & 3.46 & 13.28 \\
STR & 4,330 & 11.76 & 1.95 & 0.17 & 5.57 & 22.77 \\
BCS & 5,585 & 2.89 & 0.79 & 0.27 & 1.00 & 5.00 \\
MY & 5,634 & 34.57 & 10.20 & 0.30 & 0.80 & 90.00 \\
MF\% & 4,969 & 3.97 & 0.88 & 0.22 & 0.68 & 7.99 \\
MP\% & 5,533 & 3.01 & 0.31 & 0.10 & 1.53 & 9.33 \\
\hline
\end{tabular}

${ }^{1} \mathrm{STN}=$ skinfold thickness over the neck $(\mathrm{mm}) ; \mathrm{STR}=$ skinfold thickness over the last rib $(\mathrm{mm}) ; \mathrm{MY}=$ milk yield (kg); $\mathrm{MF} \%=$ milk fat percentage; $\mathrm{MP} \%=$ milk protein percentage.

The model for STN was $y_{i j k l}=h m_{i}+$ parity $_{j}+$ stage $_{k}$ + animal $_{i j k l}+$ residual $_{i j k l}$; the model for STR was $y_{i j k l m}$ $=h m_{i}+$ parity $_{j}+$ stage $_{k}+$ bodyside $_{l}+$ animal $_{i j k l m}+$ residual $_{i j k m}$; the model for BCS was $y_{i j k}=h r_{i}+$ stage $_{j}$ + animal $_{i j k}+$ residual $_{i j k}$; and the model for MY, MF\%, and $\mathrm{MP} \%$ was $y_{i j k l}=h y_{i}+$ parity $_{j}+$ stage $_{k}+$ animal $_{i j k l}$ + residual $_{i j k l}$, where $y$ is the dependent variable, $h m$ was a fixed effect of herd-measurer of skinfold thickness $(i$ $=1,2, \ldots, 14$, representing 14 combinations of 9 herds and 7 measurers in models for STN and STR); parity was a fixed effect of parity $(j=1,2, \ldots, 5$, representing parities $1,2,3,4$, and $\geq 5$ of cows in models for STN, STR, MY, MF\%, and MP\%); stage was a fixed effect of lactation stage $(k$ or $j=1,2, \ldots, 5$, representing 5 lactation stages as described above in models for STN, STR, $\mathrm{MY}, \mathrm{MF} \%$, and MP\%, or BCS); bodyside was a fixed effect of body side on skinfold thickness $(l=1,2,3$, representing left, not recorded, right in model for STR); $h r$ was a fixed effect of herd rater 1-herd rater 2 of BCS ( $i=1,2, \ldots, 32$, representing the 32 combinations of 9 herds and 22 rater groups consisting of 2 raters in model for BCS); hy was a fixed effect of herd-year of test-day records $(i=1,2, \ldots, 13$, representing the 13 combinations of 9 herds and 2 yr in model for BCS); animal was the random animal additive genetic effect; residual was a random residual effect, and subscript $m$ represents the $m$ th individual. The effect of year was completely confounded in the effect of herd-measurer for STN and STR and herd-rater for BCS and was not, therefore, included in the model.

\section{RESULTS}

\section{Descriptive Statistics}

The descriptive statistics for 6 traits are presented in Table 1. The STN $(7.15 \pm 1.28 \mathrm{~mm}$; mean $\pm \mathrm{SD})$ was thinner than STR $(11.76 \pm 1.95 \mathrm{~mm})$. Based on the records of 4,299 cows measured over both the neck and the last rib, the difference $(4.61 \pm 1.80 \mathrm{~mm})$ between STN and STR was strongly significant using paired $t$-test $(P<0.01)$. Both STN and STR were approximately symmetrically distributed by visual inspection (Supplemental Figure S1; https://doi.org/10.3168/jds .2018-15180).

\section{Estimates of Fixed Effects}

In this study, herd-measurer, parity, and lactation stage had significant effects $(P<0.05)$ on both STN and STR $(P<0.05)$, whereas body side had significant effect only on STR $(P<0.05)$. Estimates of parity effects on skinfold thickness are presented in Table 2. The STN decreased with increasing parity, declining, on average, by $0.49 \mathrm{~mm}$ from parity 1 to parity 5 or greater, which coincided with the decline in STR of $0.56 \mathrm{~mm}$ from parity 1 to parity 4 .

The estimates of the milking stage effect on skinfold thickness are shown in Table 3. In the normal lactation period (within $305 \mathrm{~d}$ ), both STN and STR decreased with increasing DIM, being thickest at the time of calving and thinnest in the third stage of lactation. The dif-

Table 2. Estimates of the parity effects on skinfold thickness ${ }^{1}$

\begin{tabular}{|c|c|c|c|c|}
\hline \multirow[b]{2}{*}{ Parity } & \multicolumn{2}{|c|}{ STN } & \multicolumn{2}{|c|}{ STR } \\
\hline & $\mathrm{n}$ & $\mathrm{BLUE}^{2} \pm \mathrm{SE}$ & $\mathrm{n}$ & $\mathrm{BLUE} \pm \mathrm{SE}$ \\
\hline 1 & 1,650 & $0.49 \pm 0.07$ & 1,658 & $0.49 \pm 0.11$ \\
\hline 2 & 1,302 & $0.45 \pm 0.07$ & 1,311 & $0.15 \pm 0.11$ \\
\hline 3 & 712 & $0.38 \pm 0.07$ & 713 & $-0.06 \pm 0.11$ \\
\hline 4 & 339 & $0.23 \pm 0.08$ & 342 & $-0.07 \pm 0.12$ \\
\hline$\geq 5$ & 303 & 0 & 306 & 0 \\
\hline
\end{tabular}


Table 3. Estimates of lactation stage effects on skinfold thickness ${ }^{1}$

\begin{tabular}{lrrrrr}
\hline & \multicolumn{2}{c}{ STN } & & \multicolumn{2}{c}{ STR } \\
\cline { 2 - 3 } \cline { 5 - 6 } Lactation stage & \multicolumn{1}{c}{$\mathrm{n}$} & $\mathrm{BLUE}^{2} \pm \mathrm{SE}$ & & $\mathrm{n}$ & \multicolumn{1}{c}{ BLUE $\pm \mathrm{SE}$} \\
\hline $1-50 \mathrm{~d}$ & 530 & $0.27 \pm 0.06$ & & 532 & $0.24 \pm 0.09$ \\
$51-100 \mathrm{~d}$ & 517 & $0.11 \pm 0.06$ & & 518 & $0.02 \pm 0.09$ \\
$101-200 \mathrm{~d}$ & 1,299 & $-0.01 \pm 0.05$ & & 1,307 & $-0.15 \pm 0.08$ \\
$201-305 \mathrm{~d}$ & 1,299 & $0.07 \pm 0.05$ & & 1,309 & $-0.01 \pm 0.07$ \\
$>305 \mathrm{~d}$ & 661 & 0.00 & & 664 & 0.00 \\
\hline
\end{tabular}

${ }^{1} \mathrm{STN}=$ skinfold thickness over the neck; STR $=$ skinfold thickness over the last rib.

${ }^{2} \mathrm{BLUE}=$ best linear unbiased estimator.

ference between STN and STR throughout a lactation period reached 0.28 and $0.39 \mathrm{~mm}$, respectively. In the present study, STR measured on the right-hand side of cows was $0.83 \mathrm{~mm}$ thicker than that measured on the left-hand side.

\section{Genetic Parameters}

The estimates of the variance components and heritabilities using a 6-trait model are shown in Table 4. The additive genetic variance and phenotypic variance of STR were larger than that of STN. Estimated heritabilities $( \pm \mathrm{SE})$ for STN $(0.13 \pm 0.03)$ were lower than that for STR $(0.26 \pm 0.04)$. The estimated heritabilities of $\mathrm{BCS}, \mathrm{MY}, \mathrm{MF} \%$, and $\mathrm{MP} \%$ were low, ranging from 0.07 to 0.12 .

Table 5 shows genetic and phenotypic correlations among all 6 traits. We detected a strong positive genetic correlation (0.79) between STN and STR. The genetic correlation between STN and BCS (0.33) was positive and moderate and higher than that between STR and BCS (0.18). All genetic correlations between STN or STR and milk production traits were negligible. The genetic correlations between BCS and milk production traits were moderate, ranging from -0.36 between BCS and MY to 0.30 between BCS and MP\%.

\section{DISCUSSION}

The average STR in this study $(11.76 \mathrm{~mm})$ was in the reported mean range of Holstein and Friesian populations (11.40-12.16 mm; Dowling, 1955; Patel and Anderson, 1958). The average STN in this study $(7.15 \mathrm{~mm})$ was in the reported mean range of 5 cattle populations (3.33-7.86 mm; Patel and Anderson, 1958; Hamid et al., 2000; Kshatriya et al., 2009) but lower than the reported mean range of Holstein and Friesian populations (7.80-8.10 mm; Patel and Anderson, 1958; Xie et al., 2010). These differences in skin thickness among different populations may be due to differences of genetic background, nutrition level, or measurer (Dowling, 1955; Tulloh, 1960; Hayman et al., 1966). The significant differences between skinfold thickness over the neck and the last rib found in this study were also reported in previous studies (Patel and Anderson, 1958; Tulloh, 1961; Pan, 1963). In those studies, skinfold thicknesses over 5 body regions were examined, and thickness over the elbow was the least (5.69-6.02 mm) and that over the last rib was the greatest (10.92-16.30 mm; Patel and Anderson, 1958).

Previous studies (Dowling, 1955; Brown et al., 2000) reported that the force used to pinch the fold affected the measurement of skinfold thickness. In the current study, measurer had significant effects on STR. It is highly recommended that measurers be trained for consistency and that measurer information should be recorded and included in the analysis. A difference of $0.83 \mathrm{~mm}$ between STR measured on the right-hand side and that on the left-hand side was found in the present study, which is consistent with results reported in a Hereford population (Tulloh, 1961). This could be caused by the large rumen located on the left side of the body. Therefore, body side information should be recorded, and we recommend that STR be measured consistently on one side of the body.

The only reported heritability for skinfold thickness was in Nellore cattle, where the skinfold thickness of the region posterior to the scapula was measured (Maiorano et al., 2016). The estimated heritability from that study was $0.12 \pm 0.02$ (Maiorano et al., 2016), similar to the heritability of STN and lower than that of STR esti-

Table 4. Estimates of additive genetic variance $\left(\sigma_{a}^{2}\right)$, residual variance $\left(\sigma_{e}^{2}\right)$, phenotypic variance $\left(\sigma_{p}^{2}\right)$, and heritability $\left(\mathrm{h}^{2}\right)$ of skinfold thickness over the neck and last rib, BCS, and milk production traits

\begin{tabular}{lcrrr}
\hline Trait $^{1}$ & $\sigma_{a}^{2}$ & $\sigma_{e}^{2}$ & $\sigma_{p}^{2}$ & $\mathrm{~h}^{2}( \pm \mathrm{SE})$ \\
\hline STN & 0.13 & 0.90 & 1.03 & $0.13 \pm 0.03$ \\
STR & 0.67 & 1.89 & 2.56 & $0.26 \pm 0.04$ \\
BCS & 0.05 & 0.34 & 0.39 & $0.12 \pm 0.03$ \\
MY & 8.57 & 68.56 & 77.13 & $0.11 \pm 0.02$ \\
MF\% & 0.05 & 0.66 & 0.71 & $0.07 \pm 0.02$ \\
MP\% & 0.01 & 0.07 & 0.08 & $0.08 \pm 0.02$ \\
\hline
\end{tabular}

${ }^{1} \mathrm{STN}=$ skinfold thickness over the neck $(\mathrm{mm}) ; \mathrm{STR}=$ skinfold thickness over the last rib $(\mathrm{mm}) ; \mathrm{MY}=$ milk yield $(\mathrm{kg}) ; \mathrm{MF} \%=$ milk fat percentage; $\mathrm{MP} \%=$ milk protein percentage. 
Table 5. Genetic correlations $\pm \mathrm{SE}$ (above the diagonal) and phenotypic correlations $\pm \mathrm{SE}$ (below the diagonal) for skinfold thickness over the neck and last rib, BCS, and milk production traits

\begin{tabular}{|c|c|c|c|c|c|c|}
\hline Trait $^{1}$ & $\mathrm{STN}$ & STR & $\mathrm{BCS}$ & MY & $\mathrm{MF} \%$ & $\mathrm{MP} \%$ \\
\hline STR & $0.34 \pm 0.01$ & & $0.18 \pm 0.14$ & $-0.02 \pm 0.14$ & $0.02 \pm 0.18$ & $0.02 \pm 0.17$ \\
\hline $\mathrm{MF} \%$ & $0.00 \pm 0.02$ & $-0.02 \pm 0.02$ & $0.03 \pm 0.02$ & $-0.08 \pm 0.01$ & & $0.66 \pm 0.17$ \\
\hline $\mathrm{MP} \%$ & $-0.01 \pm 0.02$ & $-0.01 \pm 0.02$ & $0.09 \pm 0.01$ & $-0.16 \pm 0.01$ & $0.28 \pm 0.04$ & \\
\hline
\end{tabular}

${ }^{1} \mathrm{STN}=$ skinfold thickness over the neck $(\mathrm{mm}) ; \mathrm{STR}=$ skinfold thickness over the last rib $(\mathrm{mm}) ; \mathrm{MY}=$ milk yield $(\mathrm{kg}) ; \mathrm{MF} \%=\mathrm{milk}$ fat percentage; $\mathrm{MP} \%=$ milk protein percentage.

mated in this study. Skinfold thickness is a trait with moderate heritability. We found a high genetic correlation between skinfold thicknesses over the neck and last rib $(0.79 \pm 0.08)$. Therefore, measurements of skinfold thickness over a few representative positions, such as over the last rib and the neck, can reflect the overall situation of skinfold thickness. Furthermore, skinfold thickness over one convenient position (either over the neck or over the rib) could be sufficient when skinfold thickness is measured for management purposes, which implies simplicity of use of skinfold thickness measurement in practice.

Skinfold thickness was found to decrease with increasing parity in the current study, and this is in agreement with previous findings of a steady increase in thickness up to the age of around $2 \mathrm{yr}$, followed by a small decrease (Walker, 1957). Only lactating Holstein cows were measured in the current study; STN declined by $0.49 \mathrm{~mm}$ from parity 1 to parity $\geq 5$, which coincided with a decline in STR of $0.56 \mathrm{~mm}$ from parity 1 to parity 4 .

The skinfold contains the subcutaneous fat (Nicholson and Little, 1989; Brown et al., 2000); therefore, skinfold thickness is significantly correlated with body fatness (Brown et al., 2000). The BCS is widely used to evaluate energy metabolic status and body fatness (Schröder and Staufenbiel, 2006; Roche et al., 2009). After calving, reductions in BCS and skinfold thickness are particularly pronounced between wk 1 and 2 due to the decrease of whole-body fat content and muscle mass; in the experiment (wk 0 to 16) reported by Bruckmaier et al. (1998), skinfold thickness remained low after the reduction, whereas BCS increased. Tamminga et al. (1997) reported rapid muscle protein mobilization after parturition, which changed to protein retention after several weeks of lactation in dairy cows. Thus, the increase in BCS after the lowest level (at wk 12 in the study of Bruckmaier et al., 1998) should be mainly due to protein retention, whereas skinfold thickness did not increase until wk 16 in the same experiment, reflecting no significant fat deposition due to a long-lasting, low-energy status until the middle of lactation in dairy cows. The current study showed that both skinfold thickness and BCS were sensitive to changes in DIM during the entire lactation, and we found changing patterns similar to those of Bruckmaier et al. (1998). Skinfold thickness remained low until the period of 101 to 200 DIM, whereas the lowest BCS were measured during the period of 51 to 100 DIM (Supplemental Figure S2; https://doi.org/10.3168/jds .2018-15180).

We estimated low to medium genetic correlations between skinfold thickness and BCS (0.18-0.33) based on the current data set, which supported our hypothesis that skinfold thickness and BCS provide complementary information about the nutrition status of cattle. Therefore, the complementary use of skinfold thickness and BCS is beneficial not only to identify the overall change in the body fat layer and energy storage but also to monitor changes in body fat deposition to achieve greater management precision with regard to energy metabolism. Skinfold thickness was genetically unrelated to milk performance ( -0.02 to 0.16$)$. We expect that selection of skinfold thickness could improve fat deposition ability without sacrificing production to facilitate balanced selection between health and production.

\section{CONCLUSIONS}

Skinfold thickness is a trait with moderate heritability. We estimated a high genetic correlation between skinfold thicknesses over the neck and the last rib in a Chinese Holstein population and a moderate genetic correlation between skinfold thickness over the neck and BCS. Skinfold thickness was poorly correlated with milk performance traits. Skinfold thickness can be easily measured and is sensitive to changes in body condition or fat deposition across parities and lactation stages in milking cows. The complementary use of skinfold thickness and BCS is beneficial to monitor changes in body fat deposition as well as changes in body fat content and muscle mass with increasing DIM to achieve higher management precision. 


\section{ACKNOWLEDGMENTS}

This study was supported by the earmarked fund for Modern Agro-industry Technology Research System (CARS-36); the program for Changjiang Scholar and Innovation Research Team in University (IRT_15R62); and Beijing Dairy Industry Innovation Team (BAIC062018, Beijing, China). We thank the Dairy Association of China (Beijing, China) for providing a pedigree.

\section{REFERENCES}

Bonsma, J. C., J. Van Marle, and J. H. Hofmeyr. 1953. Climatological research on animal husbandry and its significance in the development of beef-cattle production in colonial territories. Emp. J. Exp. Agric. 21:154-175.

Brown, D. J., M. L. Wolcott, and B. J. Crook. 2000. The measurement of skin thickness in Merino sheep using real time ultrasound. Wool Technol. Sheep Breed. 48:269-276.

Bruckmaier, R. M., L. Gregoretti, F. Jans, D. Faissler, and J. W. Blum. 1998. Longissimus dorsi muscle diameter, backfat thickness, body condition scores and skinfold values related to metabolic and endocrine traits in lactating dairy cows fed crystalline fat or free fatty acids. Zentralbl Veterinarmed A 45:397-410. https://doi.org/ 10.1111/j.1439-0442.1998.tb00842.x.

Carr, W. C., J. Macleod, B. Woolf, and R. L. Spooner. 1974. A survey of the relationship of genetic markers, tick-infestation level and parasitic diseases in Zebu cattle in Zambia. Trop. Anim. Health Prod. 6:203-214. https://doi.org/10.1007/BF02383279.

Charles, D. D. 1974. A method of estimating carcase components in cattle. Res. Vet. Sci. 16:89-94.

Chen, L. W., M. T. Tint, M. V. Fortier, I. M. Aris, L. P. Shek, K. H. Tan, S. Y. Chan, P. D. Gluckman, Y. S. Chong, K. M. Godfrey, V. S. Rajadurai, F. Yap, M. S. Kramer, and Y. S. Lee. 2018. Which anthropometric measures best reflect neonatal adiposity? Int. J. Obes. (Lond.) 42:501-506. https://doi.org/10.1038/ijo.2017.250.

Dowling, D. F. 1955. The thickness of cattle skin. Aust. J. Agric. Res. 6:776-785. https://doi.org/10.1071/AR9550776.

Ghebremariam, M. K., V. P. M. G. Rutten, J. C. M. Vernooij, K. Uqbazghi, T. Tesfaalem, T. Butsuamlak, A. M. Idris, M. Nielen, and A. L. Michel. 2016. Prevalence and risk factors of bovine tuberculosis in dairy cattle in Eritrea. BMC Vet. Res. 12:80. https:/ /doi.org/10.1186/s12917-016-0705-9.

Gregory, N. G., J. K. Robins, D. G. Thomas, and R. W. Purchas. 1998. Relationship between body condition score and body composition in dairy cows. N. Z. J. Agric. Res. 41:527-532. https://doi .org/10.1080/00288233.1998.9513335.

Hamid, M. A., S. M. I. Husain, M. K. I. Khan, M. N. Islam, and M. A. Biswas. 2000. Skin thickness in relation to milk production of crossbred cows. Pak. J. Biol. Sci. 9:1525-1529. https://doi.org/10 $.3923 /$ pjbs.2000.1525.1529.

Hayman, R. H., J. Beeston, T. E. Allen, and T. Nay. 1966. Skin thickness in Sahiwal and Jersey cattle and its measurements. J. Agric. Sci. 67:345-351. https://doi.org/10.1017/S0021859600017342.

Kshatriya, P. S., M. M. Trivedi, and A. J. Dhami. 2009. Association of udder biometry and skin thickness with milk yield in Kankrej and crossbred cows. Indian J. Field Vet. 5:11-13.

Lai-Cheong, J. E., and J. A. McGrath. 2013. Structure and function of skin, hair and nails. Medicine (Baltimore) 41:317-320. https://doi .org/10.1016/j.mpmed.2009.03.002.

Latshaw, J. D., and B. L. Bishop. 2001. Estimating body weight and body composition of chickens by using noninvasive measurements. Poult. Sci. 80:868-873. https://doi.org/10.1093/ps/80.7.868.

Lepper, A. W. D., D. A. Newton-Tabrett, L. A. Corner, M. T. Carpenter, W. A. Scanlan, O. J. Williams, and D. M. Helwig. 1977. The use of bovine PPD tuberculin in the single caudal fold test to detect tuberculosis in beef cattle. Aust. Vet. J. 53:208-213. https: //doi.org/10.1111/j.1751-0813.1977.tb00187.x.

Madsen, P., P. Sorensen, G. Su, L. H. Damgaard, H. Thomsen, and R. Labouriau. 2006. DMU-A package for analyzing multivariate mixed models. Pages 11-27 in Proc. 8th World Congr. Genet. Appl. Livest. Prod. (Vol. 247), Belo Horizonte, Brazil.

Maiorano, A. M., M. C. S. Oliveira, J. N. S. G. Cyrillo, L. G. Albuquerque, R. A. Curi, and J. A. I. Silva. 2016. Genetic study of skin thickness and its association with postweaning growth in Nellore cattle: estimation of the genetic parameters. Genet. Mol. Res. 15. https://doi.org/10.4238/gmr.15017124.

Muenchen Alfonzo, E. P., M. V. Gualberto Barbosa Da Silva, D. D. S. Daltro, M. T. Stumpf, V. C. Dalcin, G. Kolling, V. Fischer, and C. M. McManus. 2016. Relationship between physical attributes and heat stress in dairy cattle from different genetic groups. Int. J. Biometeorol. 60:245-253. https://doi.org/10.1007/s00484-015-1021-y.

Nicholson, M. J., and D. A. Little. 1989. A note on the usefulness of skinfold thickness $\mathrm{v}$. condition score for estimating body fat content in Boran cattle. Anim. Prod. 48:234-236. https://doi.org/10 $.1017 /$ S0003356100003950.

Noyce, K. V., P. L. Coy, and D. L. Garshelis. 2002. Bone prominence and skin-fold thickness as predictors of body fat and reproduction in American black bears. Ursus 13:275-284.

Pan, Y. S. 1963. Quantitative and morphological variation of sweat glands, skin thickness, and skin shrinkage over various body regions of Sahiwal Zebu and Jersey cattle. Aust. J. Agric. Res. 14:424-437. https://doi.org/10.1071/AR9630424.

Patel, U. G., and D. W. Anderson. 1958. Variation of skin thickness in dairy cattle. Emp. J. Exp. Agric 26:18-24.

Roche, J. R., N. C. Friggens, J. K. Kay, M. W. Fisher, K. J. Stafford, and D. P. Berry. 2009. Invited review: Body condition score and its association with dairy cow productivity, health, and welfare. J. Dairy Sci. 92:5769-5801. https://doi.org/10.3168/jds.2009-2431.

SAS Institute. 2004. SAS/Graph 9.1 Reference. SAS Institute Inc., Cary, NC.

Schröder, U. J., and R. Staufenbiel. 2006. Invited review: Methods to determine body fat reserves in the dairy cow with special regard to ultrasonographic measurement of backfat thickness. J. Dairy Sci. 89:1-14. https://doi.org/10.3168/jds.S0022-0302(06)72064-1.

Siddiqui, M. A. R., J. Bhattacharjee, Z. C. Das, M. M. Islam, M. A. Islam, M. A. Haque, J. J. Parrish, and M. Shamsuddin. 2008. Crossbred bull selection for bigger scrotum and shorter age at puberty with potentials for better quality semen. Reprod. Domest. Anim. 43:74-79. https://doi.org/10.1111/j.1439-0531.2007.00857.x.

Tamminga, S., P. A. Luteijn, and R. G. M. Meijer. 1997. Changes in composition and energy content of liveweight loss in dairy cows with time after parturition. Livest. Prod. Sci. 52:31-38. https:// doi.org/10.1016/S0301-6226(97)00115-2.

Tucker, C. B., A. R. Rogers, G. A. Verkerk, P. E. Kendall, J. R. Webster, and L. R. Matthews. 2007. Effects of shelter and body condition on the behaviour and physiology of dairy cattle in winter. Appl. Anim. Behav. Sci. 105:1-13. https://doi.org/10.1016/j .applanim.2006.06.009.

Tulloh, N. M. 1960. The effect of nutrition on skin and skinfold thickness in cattle. Aust. Soc. Anim. Prod. 3:192-194.

Tulloh, N. M. 1961. Variations in the skin and skin-fold thickness of beef cattle. Aust. J. Agric. Res. 12:992-1004. https://doi.org/10 .1071/AR9610992.

Walker, C. A. 1957. The skin thickness of cattle in Northern Rhodesia. J. Agric. Sci. 49:211-213.

Wildman, E. E., G. M. Jones, P. E. Wagner, R. L. Boman, H. F. Troutt, and T. N. Lesch. 1982. A dairy cow body condition scoring system and its relationship to selected production characteristics. J. Dairy Sci. 65:495-501. https://doi.org/10.3168/jds.S0022 $-0302(82) 82223-6$

Xie, Z. Q., Z. X. Xie, J. B. Liu, Y. S. Pan, X. W. Deng, L. J. Xie, J. Wen, Z. R. Zhang, and H. Q. Huang. 2010. Exploration of allergic reaction on the standard of milk water buffalo tuberculosis. Xumu Yu Shouyi 42:60-63. 